\title{
A polarização identitária e a pulverização programática no Brasil
}

DOI: 10.15175/1984-2503-202012304

\author{
Maria Alice Nunes Costa*
}

\section{Resumo}

Este artigo se propõe a realizar uma inflexão sobre a recente trajetória de mobilização social ideológica-identitária articulada no Brasil vis-à-vis ao processo de implementação da Reforma do Estado, nos anos noventa. Coadunada com as propostas neoliberais dos principais organismos internacionais de financiamento, a nova reengenharia das políticas públicas acabou por "domesticar" a pulsão transformadora da sociedade civil brasileira; e, consequentemente, a polarizou ideologicamente, fragmentando-a em polos ideológicos e identitários rivais. $\mathrm{O}$ artigo encaminha uma discussão sobre o tema, a partir das epistemologias do Sul, e tem como campo de observação empírica, os dados da atual conjuntura política, social, ideológica e identitária brasileira.

Palavras-chave: polarização ideológica-identitária; pulverização programática; políticas públicas no Brasil.

\section{La polarización identitaria y la pulverización programática en Brasil}

\section{Resumen}

Este artículo se propone reflexionar sobre la reciente trayectoria de movilización social ideológica e identitaria articulada en Brasil vis-à-vis al proceso de implementación de la reforma del Estado en los años noventa. En línea con las propuestas neoliberales de los principales organismos internacionales de financiación, la nueva configuración de las políticas públicas acabó por «domesticar» el impulso transformador de la sociedad civil brasileña y, en consecuencia, la polarizó ideológicamente, fragmentándola en polos ideológicos e identitarios rivales. El artículo plantea un debate sobre el tema a partir de las epistemologías del Sur y tiene como campo de observación empírica los datos de la actual coyuntura política, social, ideológica e identitaria brasileña.

\footnotetext{
* Socióloga, Cientista Política, Urbanista e Fotógrafa. Pós-Doutora em Sociologia pelo Centro de Estudos Sociais da Universidade de Coimbra (2007-2011, Portugal); Doutora em Planejamento Urbano e Regional pela Universidade Federal do Rio de Janeiro Instituto de Pesquisa e Planejamento Urbano e Regional da Universidade Federal do Rio de Janeiro (IPPUR/UFRJ, 2006). Estágio Doutoral na Faculdade de Economia da Universidade de Coimbra (2004-2005). Mestre em Ciência Política pela UFF (2002). Bacharel e Licenciada em Ciências Sociais pela Universidade Federal Fluminense (1988). Professora Associada da Universidade Federal Fluminense no Instituto de Arte e Comunicação Social (Departamento de Artes) e do Programa de Pós-Graduação em Sociologia e Direito da Universidade Federal Fluminense (PPGSD/UFF). Investigadora Associada do Centro de Estudos Sociais (CES, Universidade de Coimbra, Portugal). E-mail: alicecosta.rj@uol.com.br. http://lattes.cnpq.br/9049500646143779. (1) https://orcid.org/0000-0002-3437-2238
} 
Palabras clave: polarización ideológica-identitaria; pulverización programática; políticas públicas en Brasil.

\title{
Identity polarization and programmatic pulverization in Brazil
}

\begin{abstract}
The following article aims to reflect on the recent trajectory of ideological-identity social mobilization experienced in Brazil vis-à-vis the process by which State Reform was implemented in the 1990s. In line with the neoliberal prosposals of the main international funding organizations, the new reengineering of public policies effectively "tamed" the transformative drive of Brazilian civil society, and, as a consequence, polarized it ideologically, fragmenting it into rival ideological and identity poles. This article develops a discussion on the subject based on the epistemologies of the South, taking as its empirical field of observation current data representing the intersection between politics, society, ideology, and identity in Brazil.
\end{abstract}

Keywords: Ideological-identity polarization; programmatic pulverization; public policies in Brazil.

\section{La polarisation identitaire et la dispersion programmatique au Brésil}

\section{Résumé}

Cet article a pour but de proposer une réflexion sur la trajectoire récente de la mobilisation sociale idéologico-identitaire qui s'est articulée au Brésil vis-à-vis du processus de mise en œuvre de la réforme de l'État dans les années 1990. Dans la lignée des propositions néolibérales des principaux organismes internationaux de financement, la reformulation des politiques publiques a fini par « domestiquer » la pulsion transformatrice de la société civile brésilienne et, partant, par la polariser idéologiquement en la fragmentant en deux pôles idéologiques et identitaires rivaux. Cet article propose un débat sur ce thème sur la base des épistémologies du Sud et prend comme champ d'observation empirique les données de la conjoncture politique, sociale, idéologique et identitaire brésilienne actuelle.

Mots-clés : Polarisation idéologico-identitaire ; dispersion programmatique ; politiques publiques au Brésil.

\section{巴西的意识形态的分化与政策的碎片化}

\section{摘要:}

在1990年代，巴西在实施国家体制改革的过程中，在社会动员中出现了意识形态认同的分化以及政 策碎片化的问题。根据国际金融组织的新自由主义指导思想，巴西政府改革了它的公共政策，最终 “驯服” 了巴西民间社会的变革力量。在此过程中，巴西民间变革力量也分化成意识形态上对立的 两极。本文基于 “南一北” 认识论，利用目前的政治，经济与社会的统计数据，对论题进行了实证 分析与讨论。

关键词：意识形态认同两极化；政策碎片化，巴西的公共政策 


\section{Introdução}

Este artigo pretende trazer uma reflexão sobre a questão da "polarização identitária" produzida, recentemente no Brasil, vis à vis à construção de pautas da agenda de políticas públicas, em particular a partir da Reforma do Estado dos anos noventa do século XX. Neste percurso histórico, como país semiperiférico do sistema capitalista, a implementação da Reforma do Estado absorveu a energia pulsante da sociedade civil por mudanças no país, da seguinte maneira: primeiro incorporando-a para o interior do aparelho do Estado para "domesticá-la"; e, posteriormente, polarizando a sociedade em identidades rivais. Ambas estratégias de amortecimento das demandas sociais e da luta emancipatória, geraram um espaço político de rivalidades ideológicas e identitárias, fragmentando a solidariedade interna do Brasil, em um processo que caminha e se fortalece, desde os anos 2000.

O debate e as reivindicações programáticas de políticas públicas estruturais no Brasil, foram dispersadas e pulverizadas por identidades que foram, ao logo do processo histórico de formação do Estado, subalternizadas e invisibilizadas. Agora, esses grupos demandam por reconhecimento e indenização histórica, gerando um dilema para a sociedade brasileira - em pleno século XXI -, na medida em que não há como negligenciar as suas demandas e necessidades genuínas, nem tampouco destacar a importância da construção de uma consciência coletiva de solidariedade interna no país, diante dos sérios e graves problemas materiais e estruturais que precisamos enfrentar.

Neste sentido, este artigo trata do termo "polarização identitária" como um sistema que se refere à divergência e fragmentação de opiniões, visões e pontos de vista entre extremos opostos ideológicos-identitários, reproduzindo funcionalmente - aos interesses neoliberais - uma "pulverização" das programáticas de políticas públicas. O dilema identitário é a marca do panorama contemporâneo, em particular no espaço brasileiro.

A pluralidade cultural e identitária geram importantes conflitos, que podem sinalizar uma relativa vitalidade social para as mudanças. Porém, quando esses conflitos são produzidos, externa e artificialmente, por demanda do mercado de consumo ou com o objetivo de dispersar a sociedade, produz a uma fragmentação onde é difícil encontrarmos zonas de contato de solidariedade social, em prol de políticas públicas mais consistentes e estruturais de transformação emancipatória.

Na primeira parte, realizo uma inflexão sobre a relação entre ideologia e identidade e, como esses processos interagem e se interligam no "jogo das identidades" como estratégia de justificação ideológica do capitalismo financeiro. Em seguida, trato da 
trajetória da polarização ideológica no Brasil, que tem fragmentado a consciência social coletiva no país; para em seguida, na parte três, analisar como essa polarização social interna, tem tido a capilaridade para promover a pulverização de programas relevantes de políticas públicas estruturantes, onde as questões sociais foram rivalizadas por demandas pela diferença das identidades.

\section{Processos ideológicos e identitários}

\section{Meu partido É um coração partido E as ilusões estão todas perdidas Os meus sonhos foram todos vendidos [...] Meus inimigos estão no poder Ideologia Eu quero uma pra viver [...]}

(CAZUZA, ${ }^{1}$ 1988)

A palavra ideologia tem origem na Antiguidade Grega, a partir dos discursos e das retóricas sofistas pré-socráticas, constituindo-se etimologicamente da composição grega: idea ou eidea (imagem, aparência, modo de ver) + logos (estudo). De outra maneira, para os gregos idea é "ver alguma coisa", "enxergar" com os próprios olhos. Alguém que não conseguisse "ter ideias" era considerado "cego". É a partir desta tensão em "enxergar" e produzir ideologias, que me concentrarei em relação ao conceito de ideologia.

Este artigo também é influenciado pelo conceito de ideologia como uma falsa consciência, uma ilusão ou uma ideia invertida, como nos diria Marx e Engels (2007) em A Ideologia Alemã. Para estes autores, a ideologia é a tática de tornar certas ideias como verdadeiras, para serem aceitas pela sociedade, como forma de reproduzir e disseminar ideias que legitimem as ações do capitalismo, em prol de seus interesses expansionistas e de justificação.

Não negligencio o pragmatismo do senso comum da palavra ideologia citada, como exemplo, pelo cantor e compositor brasileiro Cazuza: "ideologia, eu quero uma pra viver". Ele desejava uma ideologia, porque as suas ilusões foram perdidas. Nos 1980, Cazuza descobriu que tinha AIDS/HIVISIDA e, foi fazer o tratamento nos EUA. No seu retorno ao Brasil, em razão de ser portador desta doença, sofreu o preconceito e o estigma sexual, como outras pessoas portadoras de AIDS. Diante dessa experiência, compôs a música

\footnotetext{
${ }^{1}$ Agenor de Miranda Araújo Neto, conhecido como Cazuza, nasceu no Rio de Janeiro, em 1958 e, faleceu em 1990. Foi cantor e letrista brasileiro.
} 
frente à sua desilusão com o cenário que, ao mesmo tempo em vivia o processo de redemocratização (pós-ditadura militar de 1964) e clamava pela liberdade e igualdade, possuía um comportamento conservador, moralista e preconceituoso em relação a muito fatores culturais, em particular, em relação às pessoas que foram acometidas pela doença. Isto posto, ilusão e ideologia aqui são conexas. Cazuza, assim como a maioria dos brasileiros, tinha a esperança (ou ilusão) que a redemocratização no Brasil significaria uma mudança da realidade brasileira, com os ideais da democracia, tais como: igualdade, justiça social e liberdade.

Neste cerne, podemos encontrar contradições do uso do termo ideologia. As tensões de um conceito é algo absolutamente coerente com o mundo da vida, seja ela vivida, experimentada ou percebida. Como diria o escritor Machado de Assis (1884), no conto "A Igreja do Diabo": a vida é uma eterna contradição. Nesta lógica, não existe "erro" epistemológico ao tratarmos um conceito como algo ambíguo, ambivalente e contraditório. A vida não está a serviço dos conceitos, os quais elaboramos. Os conceitos é que estão a serviço da vida em que vivemos, construímos e experimentamos sentidos. Todo conceito está em constante construção e, é desenhado, a partir dos nossos pontos de vista e, do poder hegemônico do espírito de determinada época histórica. Todos os conceitos são construções culturais de um tempo e, no caso específico, trato a ideologia como um constructo cultural per se, na medida em que está intrinsecamente relacionada à ação de viver e de nos relacionarmos em sociedade, enquanto seres viventes e pensantes, capazes de utilizarmos a nossa imaginação para nos representarmos e projetarmos a nossa visão de mundo.

Ideologia é um signo, uma imagem que construímos e representamos, fruto de nossa interação e da práxis com a vida social. É um conjunto de ideias, valores e de normas, "ditadas" de forma culturalmente "transcendental", de como devemos pensar, fazer e nos comportar, para que possamos criar - mental e culturalmente - um sentimento de identidade e pertencimento a determinado grupo ou sociedade. Está no cerne da representação mental das ideias, fruto de nossa imaginação e pensamentos construídos historicamente no campo relacional e comunicacional com o mundo. De maneira metafórica, ideologia é a fotografia que, em processo de interpretação, realizamos uma imagem da realidade. É o espelho que construímos, a partir de nossa imaginação mental, envolvendo a nossa cultura e o nosso "inconsciente ótico". ${ }^{2}$

\footnotetext{
${ }^{2}$ Expressão cunhada por Walter Benjamin (1992, p. 94). Aqui utilizada como metáfora para expressar as nossas pulsões produzidas a partir de nosso inconsciente.
} 
Quanto ao conceito de identidade, também podemos encontrar outros desafios, na medida em que possui uma forte natureza subjetiva e ideológica. Podemos transitar por vários campos do olhar: desde a nossa identidade como pessoa física com um número, impressão digital, sexo, etnia, idade, filiação, nacionalidade e naturalidade (identidade civil); peso, altura, cor e, se possui alguma deficiência (identidade corpórea), o status quo ou o lugar social identitário que ocupamos no grupo social (identidade social); o posicionamento político no campo do poder no espaço público da ágora (política de identidade), como também a partir das crenças, interesses, religiões e tradições (identidade cultural). Diante destas classificações, podemos nos questionar: Que relação existe entre as características identitárias "não-civis" de uma pessoa (ao contrário das civis, ${ }^{3}$ que são controladas pelo Estado) e a imagem que eles próprios fazem de sua identidade?

Acredito ser impossível obter a priori uma separação nítida entre as diversas classificações e diferentes características identitárias, antes de observarmos a sua interação com determinados vínculos sociais, na medida em que a identidade perde seus atributos de aparente permanência, quando interagem subjetivamente em múltiplos campos de poder e vínculos sociais. Não somos um corpo fixo em determinado espaço. Não somos um uno indivisível. O formalismo determinístico do conceito de identidade, perde-se, e nos resta invocar a observação empírica das relações sociais que flutuam e interagem, em determinados espaços e territórios.

Na prática, existe uma relação emaranhada entre ideologia e identidade, na medida em que são interdependentes e se sobrepõem-se entre si, de forma complementar. Ambos os conceitos, não permitem por si próprios, explicar a fenomenologia ideológica e identitária de cada ser subjetivo, em suas realidades concretas e simbólicas, de estar. Ser e estar são flutuantes. Por este ponto de vista, devemos desconfiar e nos interrogarmos em relação a formalismos fundamentalistas dos conceitos de ideologia e identidade, na medida em que eles estão permeados de imbricações e tensões em círculos concêntricos e dinâmicos que, em muitos casos, são inatingíveis de se compreender e analisar, no exato momento em que os fatos referentes às ideologias-identitárias ocorrem e se autodefinem, em seus universos "labirínticos". Transitamos e nos metamorfoseamos por vários campos sociais, e

\footnotetext{
${ }^{3}$ Atualmente, as identidades civis - com o avanço das ciências da vida - também podem se transformar, na medida em que, por exemplo, um "homem", pode ser transformar em "mulher" (ou vice-versa), bem como a cor, a altura e o peso podem ter suas mudanças e alterações, dependendo da capacidade financeira do indivíduo, em realizar essas mutações. Contudo, o Estado tem o controle dessas alterações civis, permitindo (ou não) a alterações a partir de Leis próprias, de cada país.
} 
assumimos vários papéis e hábitos, de acordo com o campo de poder o qual desejamos nos identificar ou disputar.

Os processos identitários e ideológicos podem ser espectros que rondam tanto as esferas de transgressão social como as de subordinação e, entrelaçados de forma transversal e subjetiva, podem gerar "emancipação ou regulação social". ${ }^{4}$ Eles se constroem em espaços limítrofes que, atuando de forma exacerbada, podem mascarar uma realidade figurada por "signos", que podem ser interpretados por várias vertentes de dominação.

Tais construções fenomenológicas de dominação, no cerne das relações sociais, determinam o grau de aproximação relacional entre a ideologia identitária que o indivíduo se autodefine em grupo, bem como a imagem construída e/ou percebida pelo "outro", para identificar a localidade do indivíduo, com o objetivo de dominá-lo. Ao invocarmos uma identidade ideológica, seja ela civil, corpórea, social, cultural, política ou subjetiva de como o indivíduo se imagina e se personifica, estará oferecendo um "rótulo" imagético, que pode ser maculado e/ou manipulado pelo "outro", distorcendo a imagem construída, para oprimir e dominar, de acordo com os seus interesses.

Temos como exemplo clássico, o "jogo de identidade", de Stuart Hall (2006). Ao analisar a estratégia conservadora do presidente americano Bush, em 1991. Hall ao utilizar o episódio dos EUA, não pretendeu julgar o fato, mas sim tomá-lo como referência, para analisar as consequências na discussão das "políticas de identidades". Segundo o autor, as identidades são contraditórias e se "deslocam" mutuamente e, suas contradições atuam atravessando indivíduos e grupos políticos. Segundo Hall, o conceito de classe social não tem servido como um dispositivo discursivo ou uma categoria mobilizadora dos variados interesses ou de todas as variadas identidades das pessoas; contudo, nenhuma identidade singular pode se alinhar a diferentes identidades como uma "identidade mestra" e única. Conforme o autor, as paisagens políticas do mundo moderno estão fraturadas por identificações rivais.

No atual cenário contemporâneo, a política de "identidades ideológicas" está sob um maior controle panóptico digital, na era dos dados algorítmicos, dominados pelo fluxo invisível do poder imperialista do capitalismo financeiro, gerando "bolhas", quase intransponíveis.

\footnotetext{
${ }^{4}$ Sobre regulação social e emancipação social ver Boaventura de Sousa Santos (1997), no livro: Pela mão de Alice: o social e o político na pós-modernidade.
} 
Em "O novo espírito do capitalismo", Boltanski e Chiappello (2002) investigaram as atuais mudanças ideológicas que têm se feito acompanhar nas recentes transformações da financeirização do capital. Se a lógica e as condutas são outras, importa perceber a (re) construção deste espírito capitalista que se desenvolve, pois é este espírito, que expressa a justificativa ideológica do "compromisso" (subliminar e inconsciente) com a opressão e a dominação financeira e, invisível do capitalismo.

Os autores apontam que um dos traços do capitalismo é a busca constante por adeptos ao sistema para legitimar-se perante estes. Isto coloca a questão de como conseguir a adesão e a legitimação se, a grande maioria das pessoas, se mostram pouco motivadas a comprometer-se com as práticas capitalistas, quando não se mostram diretamente oponentes a elas (BOLTANSKI; CHIAPELLO, 2002, p. 41). Cabe ao espírito do capitalismo - de cada época - apaziguar a inquietação suscitada; e, os autores se interrogam:

\begin{abstract}
De que maneira pode o compromisso com o processo de acumulação capitalista ser uma fonte de entusiasmo inclusive para aqueles que não serão os primeiros a se aproveitarem dos benefícios realizados? Em que medida, aqueles inscritos no cosmo capitalista, podem ter a garantia de segurança mínima para eles e seus filhos? Como justificar, em termos do bem-comum, a participação da empresa capitalista e defendê-la, frente às acusações de injustiças? (BOLTANSKI; CHIAPELLO, 2002, p. 56).
\end{abstract}

O capitalismo procura obter a adesão dos "excluídos" ou dos "transgressores" para legitimar-se, buscando - fora de si - os valores ideológicos que necessita, para garantir a sua legitimidade no sistema social. Estrategicamente, apodera-se de crenças, valores e ideologias latentes que desfrutam de uma época determinada, inclusive daquelas que the são hostis, mas que se encontram inscritas no contexto cultural e, que podem ser manipuladas. Nesta busca por argumentos orientados ao bem comum, o capitalismo se apropria de ideologias e argumentos de crítica ao capitalismo, na medida em que essas ideologias, em particular das identitárias, não o afrontam direta e estruturalmente. Conforme Boltanski e Chiavello (2002, p. 7):

O capitalismo não pode prescindir de uma orientação para o bem comum da qual extrai as razões pelas quais vale à pena aderir a ele. No entanto, sua indiferença normativa impede que o espírito do capitalismo seja gerado a partir dos seus próprios recursos. Deste modo, o capitalismo necessita da ajuda de seus inimigos, daqueles que se indignam e se opõem a ele, para encontrar os pontos de apoio morais que lhe faltam, e incorporar dispositivos de justiça, elemento sem os quais não disporia da menor propriedade. 
Os autores identificaram três espíritos, cada qual com sua própria argumentação do que é o "bem-comum": o primeiro, no final do século XIX, as argumentações giravam em torno do papel do progresso, da técnica e da ciência; o segundo, no pós-guerra, a partir dos anos 1950, com a emergência das grandes corporações. A justificação se apoiava na solidariedade institucional, na distribuição do consumo, assim como na colaboração entre as grandes firmas e o Estado, em uma perspectiva do discurso da justiça social.

E o terceiro espírito foi posto em marcha, a partir dos movimentos sociais de contracultura dos anos 1960, como um fenômeno cultural anti-estableshment. Nesta fase, se criticava o capitalismo pela produção em massa, por suas grandes organizações burocráticas, hierárquicas, pela falta de liberdade e de criatividade, à qual as pessoas eram sujeitas. Contudo, não imaginávamos que essas críticas seriam incorporadas ao capitalismo financeiro e, iriam impulsionar o surgimento de um outro modelo de justificação do capitalismo, mais relacional com os indivíduos (BOLTANSKI; CHIAPELLO, 2002, p. 58-59).

Segundo os autores, é nos anos 1990, que o capitalismo financeiro absorveu a "crítica artística" produzida dos anos 1960 e, passou a adotar as ideias criativas daqueles que estavam "excluídos" de reconhecimento, pois para os autores:

É, precisamente, o conjunto de crenças associadas à ordem capitalista que contribuem para justificar esta ordem e a manter, legitimando os modos de ação e as disposições que são coerentes com ele (BOLTANSKI; CHIAVELLO, 2002, p. 46).

No atual espírito do capitalismo, ocorre a descoberta de que o capitalismo financeiro (pós-industrial) produz diferenças. As reivindicações deixaram de se traduzir em reivindicações materialistas, tais como: o acesso dos trabalhadores aos equipamentos coletivos materiais; carga horária de trabalho digna; saneamento básico; educação; saúde; mobilidade urbana; habitação; dentre outros. Os grupos sociais anteriormente invisibilizados e/ou não-reconhecidos - de forma identitária - passaram a realizar reivindicações "pósmaterialistas", no atual modelo e contexto do espírito capitalista financeiro.

Muitos destes grupos sociais vêm secundarizando as questões materialistas e passaram a ser orientados, mesmo que de forma intersetorial, pela expansão de reivindicações de políticas identitárias, tais como: a questão de gênero; o feminismo; o homossexual; o transsexual; o racismo; a ecologia e a sustentabilidade ambiental; a postura antinuclear; o pacifismo; os direitos humanos. Os grupos sociais identitários, anteriormente, ausentes na narrativa dicotômica materialista da classe trabalhadora (dominada) e da classe capitalista (dominadora), emergiram; e, aliaram-se à novas disputas ideológicas, a 
partir da noção de "política identitária", tornando-se indispensável, a qualquer que seja o discurso político mediático contemporâneo global.

Para Jameson (1997), não se trata agora como antes, de reivindicar a transformação da infraestrutura, mas a cultura deixa de ser uma expressão relativamente autônoma da organização social e, se torna a lógica de todo o capitalismo financeiro. Para esse autor, a dissolução da esfera autônoma da cultura significa a expansão da cultura por todo o domínio do social: do valor econômico e do poder do Estado, às práticas e à própria estrutura inconsciente. A mudança dialética do capitalismo se volta agora para o visual, para a cultura da imagem da ética e da estética (como pastiche) e, de sua enorme difusão por todo o campo social (JAMESON, 2001, p. 103).

Por conseguinte, as identidades coletivas se fragmentam e se polarizam em identidades individuais e multiculturais, tornando o espaço público um lugar de demandas por reconhecimentos plurais e, ao mesmo tempo, individualizantes, que acabam por serem coerentes com o jogo do capital. A busca pelo reconhecimento da política de identidade ideológica em ser diferente, acaba por esfumaçar as demandas coletivas concretas mais genuínas e urgentes, em especial, nos territórios do Sul do mundo capitalista, como o Brasil.

\section{Polarização e pulverização da consciência coletiva}

No segundo pós-guerra, com o avanço do crescimento econômico e da capacidade reguladora do Estado nas sociedades capitalistas, formaram-se duas estruturas estatais: o Estado de Bem-Estar Social na Europa, no Canadá e na Austrália; e, o Estado desenvolvimentista nos países da semiperiferia. Na chamada "era dourada" do crescimento econômico (anos 1950 a 1970) se consolida a ideia da democracia liberal, em relação à responsabilidade do Estado pelo acesso de todos à proteção social, concebida como um direito universal. A intervenção do Estado na economia tinha, por objetivo, garantir as condições de bem-estar social, no sentido de criar a coesão social do mundo capitalista. É a partir desse "consenso" entre capital e trabalho, que se passou a exigir do Estado a proteção aos pobres e mais vulneráveis. O Estado de Bem-Estar Social foi resultado de um novo pacto social, onde capitalistas deixaram de ter algum lucro que tinham antes, em favor de um melhor funcionamento da sociedade. Em outras palavras, essa ação no seu conjunto, acabou por fortalecer o próprio capitalismo.

Segundo Swaan (1992, p. 18-19), o Estado de Bem-Estar se tornou viável em muitos países europeus porque neles se encontrou algo que pode ser chamado de "consciência 
social". Os membros da coletividade nacional estavam vinculados por uma responsabilidade que ia além da ação individual, até alcançar uma orientação de política nacional, em que o Estado proviria a segurança e a proteção dos bens coletivos.

Aliados à dominação econômica nos países periféricos e semiperiféricos, ${ }^{5}$ os países centrais puderam enfrentar, no pós-guerra, com a força do Estado, os principais problemas sociais concretos, a despeito das suas desigualdades internas, que vem aumentando, desde a crise financeira de 2008. Contudo, o Brasil - bem como os países do sul do sistema capitalista - não só não alcançaram o patamar de desenvolvimento europeu, como ainda hoje, estão longe de atingirem o mínimo de existência concreta material à maioria de seus cidadãos. No limiar do século XXI, ainda vivemos sob a subordinação geopolítica de opressão colonial, interrelacionada por vários campos e sentidos, tais como a dominação e o controle da economia, da tecnologia e do conhecimento.

O fornecimento de nossas matérias-primas é desigual e a instalação de indústrias montadoras e o uso da mão de obra barata transforma-se em trade-off colonizador. As desigualdades sociais e a concentração de renda são abruptas, com um gap estrutural exorbitante em relação aos direitos mais fundamentais de existência. Por outro lado, possuem elites empresariais, políticas e governamentais cooptadas pelo centro colonizador, operando de forma opressora e/ou autoritária, reproduzindo assim, a dominação dos países mais dominantes.

Existe um relativo consenso explicativo sobre a hegemonia da esquerda, no Brasil, em especial dos anos 2000 até 2014, em razão da alta no preço das commodities; e, a guinada para a direita populista, ser explicada em razão de que esses governos falharam, em não pensar em políticas públicas estruturais de longo prazo. Assim sendo, me questiono: em que momento da história da América Latina, em particular no Brasil, desde a sua colonização, a economia foi diversificada e não estruturada a partir de latifúndios e da exportação de matérias-primas, que hoje damos o nome de commodities?

Mesmo que não possamos negligenciar a globalização e o posicionamento do Brasil como região semiperiférica do sistema mundo, não há como ignorarmos a importância dos fatores internos, na medida em que implicaria isentarmos de responsabilidade as nossas decisões políticas pelos resultados auferidos.

\footnotetext{
${ }^{5}$ Sobre a hierarquização dos países centrais, periféricos e semiperiféricos do sistema-mundo capitalista, ver Immanuel Wallerstein (2004).
} 
Em relação aos fatores internos que fluem atualmente na pólis brasileira, analiso dois aspectos: a "polarização ideológica partidária"; e, a "polarização da política identitária". Estas polarizações, entrelaçadas, tem contribuído sobremaneira para a liquefação das decisões políticas quanto ao modelo das estruturas estatais nos âmbitos econômico e social, em prol de projetos coletivos para a construção de políticas públicas (policies) eficazes, eficientes, efetivas e inclusivas.

Quanto à polarização ideológica "partidária", trato esta dimensão no espaço conflituoso partidário da arena política (politcs), em particular no Congresso Federal do Brasil. Lugar onde representantes de partes da população, disputam e negociam objetivos, conteúdos e decisões de distribuição, em relação à materialidade das políticas públicas. A tomada de decisão de cada partido e de seus membros, individual e coletivamente, se dá por meio de um processo dinâmico, operando a partir de dada cultura política e estilos políticos "coerentes" em relação aos valores, crenças, ideais políticos, sentimentos e pontos de vistas, orientando os seus posicionamentos em relação às políticas públicas a serem adotadas.

O tema da crise da representatividade política democrática, em particular na Europa e nos EUA, esteve voltado para a perspectiva da falta de confiança e do distanciamento entre legisladores e cidadãos em relação aos anseios e na resolução das necessidades e demandas concretas dos eleitores, face à "década perdida", dos anos oitenta, em razão da crise do petróleo dos anos setenta. O mais recente livro do sociólogo catalão Manuel Castells (2018), aborda a relação entre a crise da representatividade da democracia liberal institucionalizada e a "ruptura" do processo de consolidação da democracia no mundo. $\mathrm{O}$ autor se inquieta sobre quais instrumentos legítimos a serem descobertos, para sanar esse "furacão sobre as nossas vidas".

Questiono se no Brasil a democracia representativa está em risco ou se ela ainda necessita se consolidar, na medida em que estamos em um recente processo democrático, a partir da promulgação da Constituição em 1988. Será que a nossa interpretação sobre o Brasil, deve continuar sendo analisada sob os parâmetros dos países centrais? Será que as atuais manifestações sociais de 2013, mesmo que difusas, desejavam uma ruptura com a democracia liberal? Ou seus manifestantes, em particular os jovens, estavam descontentes frente a "percepção" de uma arena política permeada e mobilizada por elites políticas e econômicas que reproduzem o nosso persistente fisiologismo e clientelismo; que, ao invés de ampliar e aprofundar a nossa democracia e redistribuir com justiça social as nossas riquezas, continuam a se apropriar delas, de maneira patrimonialista? 
Importa ressaltar, que muitas categorizações conceituais de análise sobre a democracia liberal dos países centrais, também são paradigmas de controle de poder nos países periféricos e semiperiféricos do sistema mundo, como o Brasil. A colonialidade do poder é intrínseca nestas variantes categorias de existência histórico-social dos países centrais. Quijano (2010, p. 94-95) afirma que, ao negarmos a historicidade social das realidades dos territórios do Sul, acabamos por reproduzir o sentido de totalidade hegemônica:

[...] o todo tem absoluta primazia sobre todas e cada uma das partes e que, portanto, há uma e só uma lógica que governa o comportamento do todo e de todas e de cada uma das partes. As possíveis variantes do movimento de cada parte são secundárias, sem efeito sobre o todo e reconhecidas como particularidades de uma regra ou lógica geral do todo a que pertencem.

Assim sendo, precisamos ampliar a análise reducionista entre a "esquerda" e a "direita", pelo menos, na América Latina. No Brasil, os partidos possuem ideologias móveis e efetuam mutações variadas de posicionamentos, tanto pelos membros dos partidos, como pela sua atuação programática. A polarização ideológica partidária, entre "esquerda" e "direita", atua em discursos ideológicos mediáticos, ovacionados a partir da dominação carismática de seus líderes, ${ }^{6}$ mediante a pressão internacional favorável (ou não) àqueles discursos.

Na Europa e nos EUA, a guinada conservadora deve-se a três fatores convergentes: a expansão da imigração de refugiados mulçumanos, face às guerras aos países árabes, promovidas por ambas potências, em razão da apropriação do Petróleo; os efeitos da crise econômica e financeira de 2008; e, pela expansão da disputa de poder entre EUA e a China. Nesta sequência, ao invés de visualizarmos uma polarização partidária interna nos países destas regiões, observamos o crescimento de uma coesão nacionalista. O aumento do desemprego, a queda do PIB, a forte estagnação econômica e a política de austeridade, associada ao fenômeno dos refugiados imigrantes tanto para os EUA, quanto para a Europa, geraram em cada país, uma exaltação à ideologia étnica nacional. Nos EUA, o "American First", representando as rejeições internacionalistas; e, na Europa, o lema “Europa Cristã Nacionalista”. Contudo, o fenômeno da direita nacionalista na Europa não é homogêneo, nem tampouco generalizado no continente.

No Brasil, a polarização partidária se acirra a partir de 2014, quando o Estado brasileiro admitiu a crise econômica, face a reverberação da crise financeira global de 2008. A guinada à direita conservadora-populista teve o eco interno no país, frente às forças polarizantes

\footnotetext{
6 Temos como exemplo, o atual Presidente da República do Brasil, eleito em 2018 pelo Partido Social Liberal (PSL); e, desde de novembro de 2019, afirma estar sem partido.
} 
ideológicas, que se fortaleceram diante da crise, fragmentando a nação em polos inimigos. Esta polarização no Brasil, tem tido um sentido quase fratricida, desde 2013, a partir de extremos ideológicos: a esquerda ("maré-rosa") e a direita ("maré-azul"). A esquerda teve uma hegemonia, após as ditaduras militares na região; e, não observamos a tamanha polarização na produção dos sentidos, propagado de forma raivosa, no debate do atual do espaço público, com a onda conservadora no poder. Ambos os lados, se trucidam e, não chegam a lugar nenhum. Este é o cenário do Brasil, conforme o mapa abaixo:

Mapa da Mudança Política nos Países da América do Sul

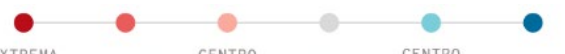

2011

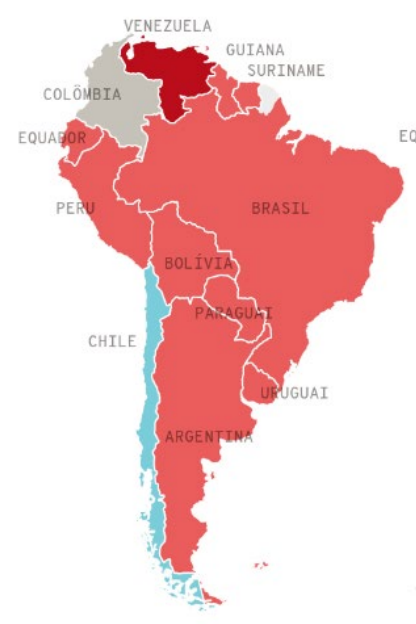

Fonte: Jornal Gazeta do Povo, Infográficos (ESQUERDA..., 2019).

Em um Estado fragmentado e polarizado como os dos territórios do sul do sistemamundo, observamos que as ondas das "marés-rosa" para a "azul", em relação aos posicionamentos partidários na América Latina, não se assemelham às mesmas explicações da Europa, mesmo diante da globalização. Nem tampouco é possível explicarmos que, diante deste Mapa da América Latina, em especial no Brasil, estaríamos à "esquerda" representando uma ruptura com o "Consenso de Washington" e das estratégias implementadas de reestruturação fiscal, com a Reforma do Estado no Brasil, desde os anos noventa.

Ao invés de estarmos vislumbrando, no Brasil, uma tentativa de ruptura ou de expressão de descontentamento com a democracia representativa, clamamos por um 
Estado forte (diferente de grande e autoritário), em prol do aprofundamento de nossa democracia e da construção de políticas públicas efetivas, a despeito das pressões internacionais colonizadoras de dominação liberalizante, que sofremos.

Ao contrário de pensarmos coletivamente as formas de atuação do Estado, no cenário de polarização, o discurso da "esquerda" brasileira acusa o atual presidente, que assumiu o poder em 2019, como: homofóbico; fascista; misógino; racista; moralizador. E os da "direita", denunciam o ex-líder que ficou no poder de 2003-2016, como: comunista; corrupto; ignorante; chefe de quadrilha. E por aí vão os discursos de acusações, mediadas por fake news na internet, tendo no debate político o foco em dois lemas, que continuam no imaginário ideológico político brasileiro: "Lula-Livre" e "Ele-Não".

Por outro lado, no sentido quase "pollyano" de enxergar o mundo, acredito que, apesar destas disputas não estarem chegando a lugar nenhum, no que diz respeito às discussões no espaço público sobre as políticas públicas implementadas pelo governo anterior, ou sobre as quais estão (ou não) sendo implementadas pelo novo governo; desde 2013, as famílias e as rodas de amigos, tem discutido frequentemente sobre política. Estamos aprendendo a diferenciar o que seja autoritarismo, totalitarismo, populismo de esquerda e de direita. Tem sido um caminho de aprendizagem, diante da nossa recente história de democracia. Por outro lado, é desalentador observarmos que as discussões têm gerado a fragmentação dos laços de solidariedade entre colegas de trabalho, amigos e familiares, quando chegam até mesmo à violência física.

No bojo da crise econômica associada à polarização partidária, passamos a observar o crescimento de uma exorbitante "polarização identitária" no Brasil. Essas "políticas identitárias" são um conjunto de retóricas de coletivos que, por não terem sido reconhecidos histórica e culturalmente como identidade hegemônica, reivindicam ser recompensados e indenizados historicamente. Nesta retórica, estamos substituindo "um tipo de tirania por outro" (APPIAH, 1994, p. 163). De acordo com Sonia Kruks7 (2001, p. 85, tradução nossa):

O que faz da política de identidade um afastamento significativo das formas anteriores e "pré-identitárias" da política de reconhecimento é sua demanda por reconhecimento, com base nas mesmas bases em que o reconhecimento foi negado anteriormente: são os grupos de mulheres, negras e lésbicas que exigem reconhecimento. A demanda não é para a inclusão no interior da "humanidade universal", com base em atributos humanos compartilhados; nem é por respeito

\footnotetext{
7 What makes identity politics a significant departure from earlier, pre-identarian forms of the politics of recognition is its demand for recognition on the basis of the very grounds on which recognition has previously been denied: it is qua women, qua blacks, qua lesbians that groups demand recognition. The demand is not for inclusion within the fold of "universal humankind" on the basis of shared human attributes; nor is it for respect "in spite of" one's differences. Rather, what is demanded is respect for oneself as different.
} 
"apesar das" diferenças de alguém. Pelo contrário, o que se exige é o respeito por si mesmo, como diferente.

Embora concordando que o reconhecimento e a redistribuição sejam de fundamental importância na política pública contemporânea, Nancy Fraser lamenta a supremacia de perspectivas que levam a injustiça social, ao incorporar as construções "culturais" de identidade. Para a autora, tais modelos de reconhecimento exigem remédios que valorizem também grupos e pessoas sem identidade grupal, reconhecendo suas especificidades e tornando as abstrações identitárias - produtos de estruturas opressivas, em concretudes sociais emancipatórias (FRASER, 1997, p. 19).

Asad Haider, no seu livro, Mistaken identity: race and class in the age of Trump, publicado em 2018, afirma que a política identitária acabou por dividir a esquerda. Segundo o autor, o movimento identitário começou nos EUA com o coletivo de mulheres socialistas lésbicas, em 1977 (Coletivo Combahee River), que defendiam a construção de uma solidariedade com outros grupos progressistas, com o objetivo de eliminar ou mitigar todas as formas de opressão, ao mesmo tempo em que clamavam sobre os seus próprios sofrimentos de opressão. No entanto, suas reivindicações foram cooptadas pelo processo neoliberal, criando opressões entrecruzadas, que geram um divisionismo social, ao invés de estimular a solidariedade. Segundo Haider (2018), o enquadramento da política de identidade, tal como caminha, reduz a política ao que o indivíduo diz que é, no sentido de obter o seu reconhecimento como indivíduo e não como "sujeito social" que participa em uma coletividade, na luta coletiva contra uma estrutura social opressora, necessária a um novo "universalismo insurgente".

No Brasil, estamos vivenciando uma espécie de "mercadorização" das identidades. O espírito do capitalismo financeiro absorveu a política identitária e, paradoxalmente, criou um ambiente em que a afirmação das identidades acabou reforçando as mesmas normas, que se dispôs - anteriormente - a criticar.

Neste diapasão, está longe de minha prática intelectual e de minha consciência política emancipatória e democrática, considerar que as diferenças devem ser negadas ou silenciadas, na medida em que "Falar é passar a existir absolutamente para o outro" (FANON, 2008, p. 33). Tenho ciência que o homem branco e heterossexual eurocêntrico representa a imagem do opressor, como um signo. "Amanhã", o opressor pode possuir outra face... Como intelectual orgânica, tenho a consciência histórica da dominação, da opressão e da "tanatopolítica" em relação aos negros; dos pobres que morrem nos corredores e nas filas dos hospitais; da guerra perdida às drogas, que só matam crianças 
e trabalhadores das favelas; das tribos indígenas dizimadas por colonizadores nacionais e internacionais em busca de ouro e riqueza; da violência física e simbólica em relação às mulheres e às comunidades LGBTQQICAPF2K. ${ }^{8}$ Tenho ciência empírica das ratazanas que comem bebês em regiões ribeirinhas das periferias urbanas; da falta de água, saneamento e luz; da desqualificação profissional concreta e simbólica, produzida pelo poder masculino, em relação às mulheres; dos jovens que saem das escolas públicas, sem saber ler e escrever; do desemprego exorbitante que nos retira a dignidade humana. Tenho plena consciência do racismo estrutural, da homofobia, da transfobia; e, dos extremos fascismos sociais tanto da direita, como da esquerda. Tenho consciência das mazelas sociais concretas, simbólicas e subjetivas que assolam o Brasil, por meio da colonialidade do poder dos países centrais. Acredito que todos nós somos diferentes. E é esta diferença, que nos unifica como seres humanos e cidadãos. Faço das palavras de Boaventura de Sousa Santos (2003, p. 53), a minha ressalva:

Temos o direito a ser iguais quando a nossa diferença nos inferioriza; e, temos o direito a ser diferentes quando nossa igualdade nos descaracteriza. Daí a necessidade de uma igualdade que reconheça as diferenças e de uma diferença que não produza, alimente ou reproduza as desigualdades.

Temo não só pelo essencialismo exacerbado das "políticas de identidade", mas como essas identidades estão sendo manipuladas pelo poder mediático dos grandes grupos detentores dos meios de comunicação. Estes grupos associados ao poder do capital financeiro têm criado um espaço fabuloso e espetacular, dispersando o espaço público e criando o esvaziamento da atenção aos reais e estruturais problemas que o Brasil precisa enfrentar. Ao invés de nos unirmos e focarmos nas questões sociais concretas que o Brasil precisa enfrentar, o assunto de afirmação e de reconhecimento de políticas de identidade tem substituído o tema da política mais ampla. Não há apenas a perda do universal, mas do espaço público comum. O problema, segundo Janine Ribeiro (2000), está no tipo de reivindicação desses grupos, que acentuam a homogeneidade de seus membros, até conceber que somente seja possível a relação social "entre iguais".

\footnotetext{
${ }^{8}$ Com o intuito de expandir as caracterizações da comunidade LGBT, cito a sigla "LGBTQQICAPF2K+7, segundo alguns ativistas do Reino Unido, para significar, em inglês: L - lesbian; G - gay; B - bissexual; T transgender, Q - queer, Q - questioning; I - intersex; A - assexual; A - agender; A - ally; C - curious; P pansexual; $\mathrm{P}$ - polysexual; $\mathrm{F}$ - friends and Family; 2 - two-spirit; $\mathrm{K}$ - kink (gíria em inglês-britânico, que significa excitação sexual ou fetiche).
} 


\section{A pulverização programática das políticas públicas no brasil contemporâneo}

Os anos 1990 ganhou a preponderância de uma agenda pública neoliberal, com a estruturação de um Estado mínimo. Na América Latina, em particular no Brasil, este receituário internacional tem tido um efeito quase devastador, devido a fragilidade já existente do Estado. O ajuste estrutural com a Reforma do Estado terminou por desorganizar os mínimos direitos sociais conquistados. Dito isto, é fulcral atentarmos para a importância do Estado na formulação e implementação de políticas públicas para o Brasil, na medida em que ainda não pode ser substituída, simplesmente, pela pretensa alocação eficiente do mercado. São necessários, ainda, novos mecanismos institucionais estatais que possam dialogar com a diversidade de trajetórias sociais e cotidianas de sofrimento e morte, que acometem a maioria da população brasileira que vive sob vulnerabilidade socioeconômica, diante da nossa exorbitante desigualdade social, escancarada no cenário da pandemia do COVID19.

Pensar sobre a programática de políticas públicas em regiões e territórios periféricos, impõe sérios desafios às epistemologias do Sul. A formulação de dadas políticas (policies) é realizada a partir de diagnósticos sociais que precisam envolver o debate e o diálogo entre uma pluralidade de atores sociais, ao lado das instituições estatais. É no espaço conflituoso da arena política (politcs) que se disputam interesses e necessidades. Portanto, as políticas públicas são o resultado da materialidade de disputas e de decisões políticas. Contudo, vale lembrar que, no espaço Sul do sistema-mundo, as políticas públicas são intercambiadas e insuladas burocraticamente no aparelho do Estado tanto por interesses de elites econômicas e políticas fisiológicas, quanto pela forte interferência de pressões e constrangimentos de instituições multilaterais internacionais, como contrapartida de apoio financeiro ao desenvolvimento destas políticas.

Nesta conjuntura, realizo uma breve retrospectiva para compreendermos que a exacerbada polarização social, imbuída de reivindicações identitárias difusas, enfraquece e agrava o diálogo na esfera pública, fragilizando sobremaneira as demandas por políticas públicas fortes e estruturais ao Estado brasileiro.

Frente à crise fiscal originária das crises do petróleo dos anos setenta, o receituário foi o de compartilhar responsabilidades com a sociedade, na resolução dos problemas sociais. As agências internacionais passaram a questionar e interpretar a matriz "estadocêntrica" como nociva ao desenvolvimento econômico e social dos países. A natureza da intervenção estatal e os caminhos da reforma do Estado transformaram-se em 
grandes temas na agenda brasileira. Iniciou-se a proposta de se radicalizar o corte com o modelo de intervenção do passado, até alcançar uma reestruturação do papel do Estado, ainda em processo no Brasil.

Contudo, os países da América Latina apresentaram o "paradoxo neoliberal" produzido pelas agências multilaterais, em especial, pelo Banco Mundial. Os países que obtiveram melhores resultados com a incorporação de mecanismos de mercado, foram os de instituições políticas fortes. Foram os núcleos de coordenação do Estado que puderam viabilizar o bom funcionamento do mercado, que não diminuiu a distância entre os ricos e os milhões de pobres.

Concomitantemente, a máquina burocrática abriu canais de comunicação e criou novas institucionalidades jurídicas para promover a participação social, no recente processo democrático. Assim, a energia solidária mobilizada para o enfrentamento dos problemas sociais cotidianos foi capturada para o interior do aparelho estatal, com o objetivo de "domesticar" impulsos mais conflitantes de luta social.

O referencial do Banco Mundial, sobre a importância do capital social, serviu para garantir o fortalecimento de organizações sociais não-estatais; e, consequentemente, para garantir a execução eficiente de programas governamentais de compensação social, propostos e financiados pelas agências multilaterais de desenvolvimento, face ao contexto de ajuste estrutural, liberalização da economia e privatização do patrimônio do Estado. A nova configuração institucional "sociocêntrica" produziu a expectativa de que a transferência de responsabilidade do Estado para outras instâncias sociais, poderia tornar o Estado mais eficaz e eficiente para promover a coesão social e garantir a governabilidade. Criou-se uma revitalização da participação social, a partir do conceito de capital social, no intuito de fomentar o debate sobre as questões sociais.

No movimento de retração estatal dos anos 1990, o poder antes localizado no Estado, se estendeu por uma rede de relações e por campos setoriais, como grupos de mulheres, de jovens, de aposentados, grupos étnicos, ambientalistas, dentre outros. Surgiram as Organizações Não-Governamentais (ONGs) como canais não-oficiais dando apoio internacional a microprojetos sociais, dirigidos para o nível local. As iniciativas da sociedade civil apontaram para o surgimento de uma nova cultura política no Brasil, uma vez que as práticas sociais passaram a ser orientadas por um novo nível de condutas, normas e valores em relação ao interesse público. 
Nesta trajetória, a mobilização social dos anos noventa veio impulsionar uma capacidade artificial da sociedade para se mobilizar, em função de uma proposta de participação social "domesticada" pelo Estado. Surge uma pluralidade de atores sociais disputando e convergindo seus próprios interesses, diante das incertezas e da precariedade social. Conforme Montaño (2002, p. 272), desde os anos oitenta, o Banco Mundial - como representante das ideias neoliberais, aumentou a destinação de verbas para organizações não-governamentais, com o objetivo de cooptar as lideranças sociais e amortecer os ideários de luta que emergiam na América Latina. Assim, observamos nos anos noventa, um recuo das propostas emancipatórias dos movimentos sociais. Como resultado, ao invés de pensar a sociedade como um todo, as ONGs passaram a elaborar projetos sociais em parceria com organismos internacionais, diante do capital social e bases de informações disponíveis de grupos que tinham o mérito para assegurar a negociação nesta parceria.

Nesta trajetória de incentivo à participação social, nos anos 2000, a ação social passou a ser pulverizada por identidades de grupos sociais não-reconhecidos. As políticas identitárias passaram a atacar a desigualdade, mediante a força daqueles que passaram a ter uma "voz" mais forte no mercado consumidor, como por exemplo, os homossexuais e as mulheres negras de classe média, com potencial consumidor.

A expansão das políticas identitárias foram implementadas no Brasil face às metas a serem atingidas pelos Objetivos do Milênio (UNITED NATIONS, 2000), que tinha dentre os seus objetivos, a promoção da igualdade entre sexos e a autonomia das mulheres. Nos anos 2000, pudemos observar o poder judiciário coadunando com os Objetivos do Milênio, passando a atuar ativamente em pautas progressistas identitárias, por meio da onda da "judicialização da política". Com o aval do Supremo Federal, a partir dos anos 2002, passamos a adotar políticas públicas compensatórias, dando origem a um "novo populismo". Ao invés de políticas públicas redistributivas estruturais, o Brasil passou a focar em "políticas focais de cotas", tais como: cotas raciais; para indígenas; cotas para estudantes de escolas públicas; para transsexuais; e, cotas para mulheres na política parlamentar. Consequentemente, os grupos sociais identitários que antes estavam excluídos do debate e da formação escolar universitária, em especial os jovens, passaram a lutar pelo reconhecimento de suas identidades. Contudo, as políticas de cotas - isoladas - não representam nenhuma transformação estrutural na sociedade brasileira. Não há como negar a sua importância, na medida em que há mais mulheres, pobres, negros e indígenas nas universidades públicas; e, há mais mulheres denunciando a violência. 
No entanto, quantas vezes debatemos e pressionamos, na ágora, sobre como elevar o patamar da qualidade da educação pública do ensino fundamental, médio, profissionalizante e superior no Brasil, em especial para estes grupos minoritários? Quais medidas estruturantes que o Estado tem tomado para mitigar o desemprego? Que estratégias precisam ser fomentadas para o investimento na saúde, na ciência e na tecnologia? Qual a prospecção de políticas públicas a serem elaboradas em relação à infraestrutura brasileira, ao saneamento básico, à habitação, às ferrovias e ao transporte público? Enfim, o que mudou estruturalmente no Brasil, desde 1988, até os dias atuais?

No limiar do século XXI, o governo brasileiro - a despeito da globalização financeira - negligenciou a crise econômica americana e europeia de 2008, provavelmente, em função do possível efeito da publicização da crise vir afetar as eleições presidenciais de 2010. A crise somente foi incorporada no Brasil, "oficialmente" pelo governo federal, em 2014. No entanto, a crise já desenfreava uma demanda de trabalho, atingindo graus sérios, principalmente entre os jovens. Eles sentiam em suas vidas concretas e simbólicas, como ela os afetava. O sentimento de desesperança destes jovens abalou a credibilidade em relação aos políticos e governos, na medida em que foram duramente afetados pela expansão e dimensão da crise econômica mundial, conforme gráfico ${ }^{9}$ abaixo:

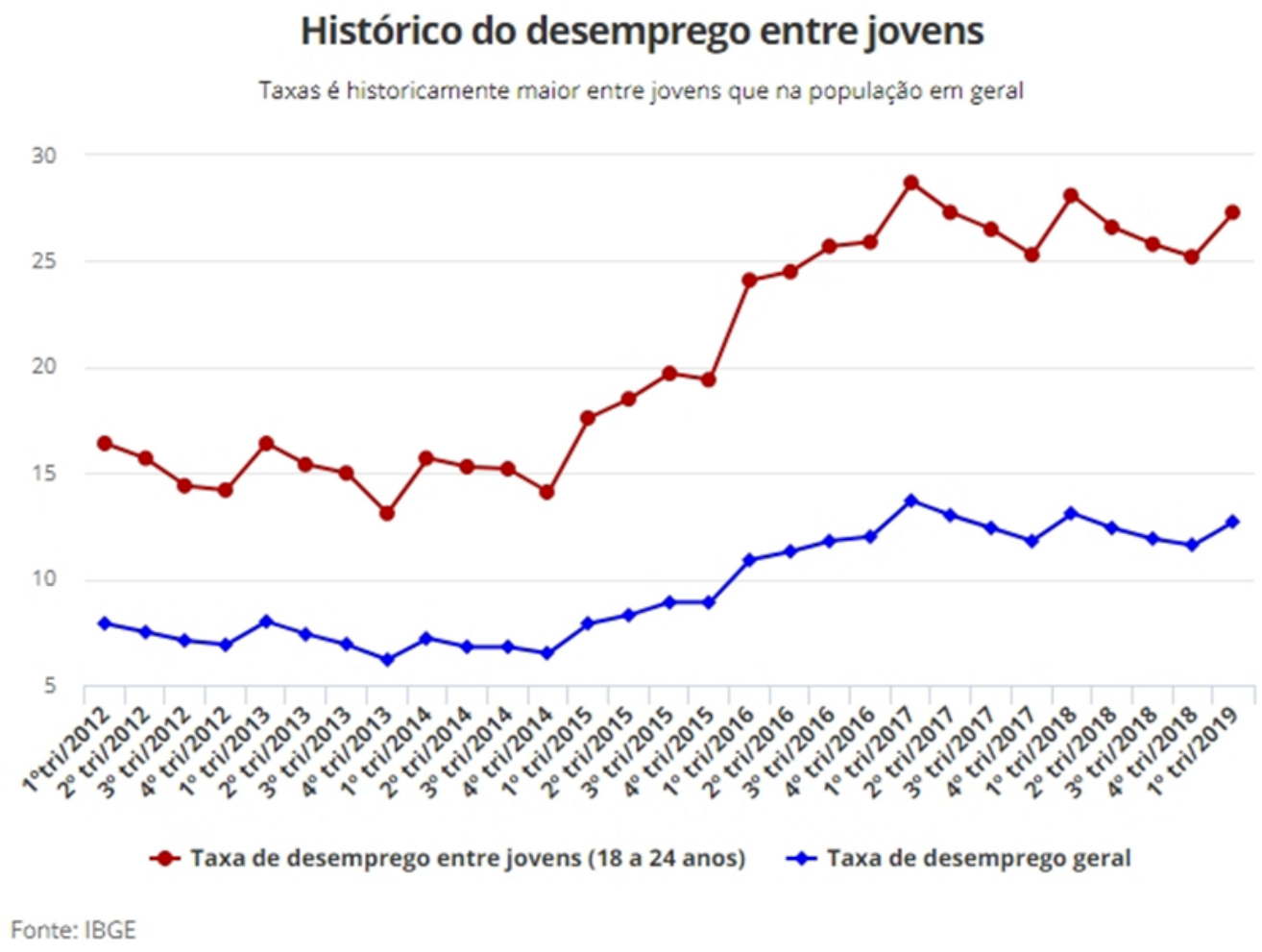

${ }^{9}$ CEERT - Centro de Estudos das Relações de Trabalho e Desigualdades, 2019. 
O percentual de jovens pobres desempregados aparece menor no gráfico oscilando desde 2012 porque, dentre outras razões, grande parte deles não estava procurando emprego. Com o fluxo da estagnação econômica, muitas famílias - que conseguiam manter seu filho estudando por mais tempo, já não conseguiam mais e, começaram a pressionar a taxa de desemprego. Como consequência, tivemos as manifestações de jovens em 2013, criando um espaço capilarizado de mobilização cidadã. Suas reivindicações, mesmo que difusas, puderam nos sinalizar a situação socioeconômica em que eles se encontravam: sem perspectiva de emprego e vivendo em situação de total desesperança.

As manifestações de 2013 retrataram o descontentamento e a insatisfação generalizada de jovens, em relação as opções das lideranças políticas nacionais. Como as reivindicações eram difusas, pulverizaram a vida política por meio das polarizações ideológicas que se distorceram e se reverberaram nas mídias por meio de polos rivais, pressionando os governos a atuar com a força da violência, ${ }^{10}$ amortecendo sua luta. Consequentemente, a força pulsional dos jovens para a transformação de mudanças estruturais no Brasil, foi redirecionada para a polarização ideológica-identitária. Elas se fortaleceram com vigor, mobilizando-se centradas sobre uma problemática de identidade e afirmação, em busca de reconhecimento. Deixou-se de discutir sobre as desigualdades, para se discutir as diferenças. O meio em que esse movimento social evoluiu não era mais o espaço político e institucional; mas, aquele formado por grupos autônomos, sem objetivo de elaborar uma nova concepção mais geral de sociedade, a partir de um projeto coletivo mais amplo. Consequentemente, o poder de integração social que poderia ser capaz de resistir às forças hegemônicas se esgotou, propiciando espaço para amortecer as energias pulsantes da esfera pública para o fortalecimento da democracia brasileira.

$\mathrm{Na}$ esteira deste horizonte pulverizado e polarizado de forma ideológica-identitária criou-se, paradoxalmente, um espaço extremamente favorável para a penetração e difusão do discurso de uma coesão nacionalista-conservadora interna: "Brasil acima de tudo, Deus acima de todos".

Urge, portanto, a emergência de intelectuais e lideranças políticas com coragem de substituir a "microética" por uma "macroética" capaz de articular a responsabilidade de todos e, unir-se com as forças contrárias à subalternização colonialista brasileira. Para isso,

\footnotetext{
10 Temos como exemplos jurídicos da força imperativa do Estado contra as manifestações de 2013, a Lei Federal $n^{\circ} 12.850$ (Lei de Organização Criminosa [BRASIL, 2013]), promulgada pela presidente Dilma Rousseff, em dois de agosto de 2013; e, a Lei Estadual n 6.528 (Lei Contra as Máscaras [RIO DE JANEIRO, 2013]), promulgada pelo então governador do Rio de Janeiro, Sergio Cabral, em 11 de setembro de 2013.
} 
é mister envolver as pautas identitárias conjuntamente e, de forma interseccional, com a elaboração de pautas de conteúdo concreto de políticas públicas amplas e inovadoras, sendo capaz de podermos desconstruir substancialmente o "estado das coisas como são", intrínsecas de nossa desigualdade estrutural; e, assim, caminhar em prol de uma coesão e reconstrução social emancipatória, garantindo projetos coletivos universalizantes para a efetividade material dos direitos sociais, às cotas-partes da sociedade, que são a maioria deste Brasil: os pobres, que vivem em seus cotidianos, os efeitos perversos contínuos de uma sociedade marcada pela escravidão.

\section{Considerações finais}

O ambiente do fortalecimento do capitalismo financeiro teve o poder, não só no mundo, mas principalmente nas regiões semiperiféricas do sistema-mundo, de manipular a produção dos nossos sentidos, polarizando ideologias e identidades. As reivindicações pósmaterialistas se fortaleceram, principalmente, em relação ao reconhecimento das identidades, que foram e são historicamente subalternizadas. No Brasil, as pautas identitárias tiveram um enorme apreço pelo Supremo Federal, que resultou no processo de "judicialização da política", sendo utilizado por grupos políticos com interesses particulares, dispersando e interferindo no debate político, sobre as políticas públicas. O capital social mediático com maior poder de pressão, foram aqueles que tinham o melhor "advogado" para catalisar as identidades no "jogo político identitário", nas mídias.

A matriz neoliberal associada à financeirização do capital, acabou por incorporar as novas demandas ideológicas e responder a elas, para se justificar e se legitimar no sistema mundo capitalista contemporâneo. A estratégia encontrada para a expansão do capitalismo financeiro, aliada à retração do Estado, ao desenvolvimento tecnológico e à robotização da mão de obra, vem gerando o aumento exacerbado do desemprego e das desigualdades sociais. Consequentemente, o poder hegemônico realiza a captura ideológica dos movimentos culturais identitários, polarizando-os, no sentido de controlá-los; e, "domesticando" as reivindicações de reconhecimento pelas diferenças culturais. Essas "críticas artísticas" não abalam as concretas estruturas do atual capitalismo financeiro; no entanto, impactam sobremaneira na vida concreta das sociedades e populações mais frágeis.

A solidariedade construída em torno desses coletivos ou movimentos sociais identitários é uma resposta individualista que tem se tornada hegemônica frente às questões sociais, no Brasil. Deixa de ser uma resposta da responsabilidade do Estado ou 
da responsabilidade de todos, que contribuem compulsoriamente para o financiamento do Estado. Agora, predomina no discurso mainstream a autorresponsabilidade de indivíduos, inclusive daqueles que possuem mais necessidades. Ou por outro lado, talvez só nos resta, ao sul do sistema capitalista, políticas compensatórias de afirmação da diferença.

O que está em jogo na política partidária na América Latina, não é o conteúdo programático dos partidos, na arena política, na medida em que quem vence é aquele que terá o maior grau de carisma mediático, seja no poder executivo, judiciário ou legislativo, para reproduzir os anseios de dominação, em relação ao jogo do poder político e econômico do capital financeiro.

Sem infraestrutura, produtividade, emprego e setores eficientes nas áreas de saúde, educação, ciência e tecnologia, o poder geopolítico global estará sempre conduzindo o sul do sistema mundo e, nos "norteando" para atuarmos politicamente de maneira polarizada: não a partir das desigualdades, mas pelas diferenças identitárias.

A nossa energia pulsante e transgressora é cooptada para o interior do aparelho burocrático, domesticando-a e, pulverizando as demandas. Ao invés de criarmos uma consciência coletiva, em prol de um projeto emancipatório, em particular no Brasil, as famílias e as instituições políticas se fragmentam e não se articulam. Creio que as mudanças, infelizmente, ainda estão longe de se concretizarem. Quiçá, em outro momento... Oxalá!

\section{Referências}

APPIAH, Anthony. Identity, authenticity, survival: multicultural societies and social reproduction. In: GUTMANN, Amy (Ed.) Multiculturalism. Princeton: Princeton University Press, 1994. p. 149-164.

ASSIS, Machado de. A Igreja do Diabo. Volume de contos. Rio de Janeiro: Garnier, 1884. Disponível em: http://www.dominiopublico.gov.br/download/texto/bv000195.pdf. Acesso em: 12 mar. 2020.

BRASIL. Presidência da República. Casa Civil. Subchefia para Assuntos Jurídicos. Lei $n^{\circ}$ 12.850, de 2 de agosto de 2013. Define organização criminosa e dispõe sobre a investigação criminal, os meios de obtenção da prova, infrações penais correlatas e o procedimento criminal; altera o Decreto-Lei n 2.848, de 7 de dezembro de 1940 (Código Penal); revoga a Lei $n^{\circ}$ 9.034, de 3 de maio de 1995; e dá outras providências. 2013. Disponível em: http://www.planalto.gov.br/ccivil_03/_Ato2011-2014/2013/Lei/L12850.htm. Acesso em: 12 mar. 2020.

BENJAMIN, Walter. Pequena história da fotografia. In: linguagem e política. Lisboa: Relógio d’Água, 1992. p. 115-135. . Sobre arte, técnica, 
BOLTANSKI, Luc; CHIAPELLO, Ève. El nuevo esprito del capitalismo. Madri: Akai, 2002.

CASTELLS, Manuel. Ruptura: a crise da democracia liberal. Tradução de Joana Angélica d'Avila Melo. São Paulo: J. Zahar, 2018.

CAZUZA; FREJAT, Roberto. Ideologia. In: CAZUZA. Ideologia. [S.I.]: PolyGram, 1988. 1 disco sonoro. Lado A, faixa 1.

ESQUERDA e direita na América do Sul. Gazeta do Povo, 10 dez. 2019. Disponível em: https://infograficos.gazetadopovo.com.br/mundo/esquerda-e-direita-na-america-do-sul/. Acesso em: 3 mar. 2020.

FANON, Frantz. Pele negra, máscaras brancas. Salvador: EdUFBA, 2008.

FRASER, Nancy. Justice interruptus: critical reflections on the "post-socialist" condition. New York: Routledge, 1997.

HAIDER, Asad. Mistaken identity: race and class in the age of Trump. London: Verso, 2018.

HALL, Stuart. A identidade cultural na pós-modernidade. Rio de janeiro: DP\&A, 2006.

JAMESON, Frederic. Pós-modernismo ou a lógica cultural do capitalismo tardio. Rio de Janeiro: Ática, 1997.

JAMESON, Frederic. A cultura do dinheiro: ensaios sobre a globalização. Petrópolis, RJ: Vozes, 2001.

KRUKS, Sonia, Retrieving experience: subjectivity and recognition in feminist politics. Ithaca, NY: Cornell University Press, 2001.

MARX, Karl; ENGELS, Friedrich. A Ideologia Alemã. 3. ed. Tradução de Luis Claudio de Castro e Costa. São Paulo: Martins Fontes, 2007.

MONTAÑO, Carlos. Terceiro setor e a questão social: crítica ao padrão emergente de intervenção social. São Paulo: Cortez, 2002.

QUIJANO, Aníbal. Colonialidade do poder e classificação social. In: SANTOS, Boaventura de Sousa; MENESES, Maria Paula (Org.). Epistemologias do Sul, São Paulo: Cortez, 2010. p. 84-130.

RIBEIRO, Renato Janine. A sociedade contra o social: o alto custo da vida pública no Brasil. São Paulo: Companhia das Letras, 2000.

RIO DE JANEIRO (Estado). Assembleia Legislativa do Estado do Rio de Janeiro. Lei $n^{\circ}$ 6528 de 11 de setembro de 2013. Regulamenta o artigo 23 da Constituição do Estado. 2013.

SANTOS, Boaventura de Sousa. Pela Mão de Alice: o social e o político na pósmodernidade. 4. ed. São Paulo: Cortez, 1997. 
SANTOS, Boaventura de Sousa. Reconhecer para libertar: os caminhos do cosmopolitanismo multicultural. Rio de Janeiro: Civilização Brasileira, 2003.

SWAAN, Abram de. A cargo del estado. Barcelona: Pomares-Corredor, 1992.

UNITED NATIONS. United Nations Millennium Declaration Resolution adopted by the General Assembly. 18 Sept. 2000. Disponível em: https://www.un.org/en/development/desa/population/migration/generalassembly/docs/glob alcompact/A_RES_55_2.pdf. Acesso em: 26 dez. 2013.

WALLERSTEIN, Imannuel. World-systems analysis: an introduction. Durham: Duke University, 2004. 